\title{
Coeliac disease and malignancy of the duodenum: diagnosis by endoscopy, successful treatment of the malignancy, and response to a gluten free diet
}

\author{
M J Hall, B T Cooper, N Rooney, H Thompson, A E Read
}

\begin{abstract}
A patient presented with subtotal villous atrophy and a malignant duodenal tumour of uncertain histiogenesis. He was successfully treated by resection and chemotherapy and the small bowel mucosa recovered on a gluten free diet. The tumour was diagnosed at upper gastrointestinal endoscopy when barium studies and abdominal computed tomography were normal, thus making this one of the earliest coeliac malignancies diagnosed.
\end{abstract}

Patients with coeliac disease are at considerable risk of developing lymphoma. ${ }^{1-3}$ Most coeliac lymphomas are of one type but their precise characterisation has been unclear. Recent evidence suggests that they are $T$ cell lymphomas. ${ }^{+6}$ Coeliac lymphoma affects the gut in about $80 \%$ of cases and is nearly always widely disseminated at diagnosis; consequently the prognosis is very poor with few patients surviving beyond six months. ${ }^{37}$ Other malignant tumours (carcinomas of the oesophagus and of the small bowel) are also seen in patients with coeliac disease. ${ }^{13}$

We report on a patient who presented with subtotal villous atrophy and a malignant duodenal tumour of uncertain histiogenesis.

\section{Case report}

A 64 year old retired plant engineer was referred from a local hospital for investigation of steatorrhoea. He gave a history of loose offensive stools, abdominal swelling, and lethargy for five years. $\mathrm{He}$ had been well as a child but at the age of 58 sustained a mild right sided hemiparesis. The following year he presented to his local hospital with abdominal pain and at laparotomy adhesions around the duodenum were found. His only drug history was soluble aspirin $300 \mathrm{mg}$ daily which he had taken since the onset of the hemiparesis. His alcohol intake was moderate and there was no relevant social or family history.

On examination he was not ill; abdominal distension and operation scars were noted. $\mathrm{He}$ did not have lymphadenopathy, hepatomegaly, or splenomegaly. Rectal examination and sigmoidoscopy were normal.

His haemoglobin concentration was $127 \mathrm{~g} / \mathrm{l}$ with a mean cell volume of $78 \mathrm{fl}$ and a reduced mean cell haemoglobin $(24 \cdot 1 \mathrm{pg})$. His plasma viscosity was raised at $1.77 \mathrm{cp}$ and $\mathrm{C}$ reactive protein raised at $14 \mathrm{mg} / \mathrm{l}$. The serum ferritin concentration was low at $9 \mu \mathrm{g} / \mathrm{l}$. Alkaline phosphatase was raised at $16 \mathrm{KA}$ units and serum $\operatorname{IgM}$ raised at $2 \cdot 5 \mathrm{~g} / 1$. The following blood tests were normal: total and differential white cell count, platelet count, prothrombin time, serum vitamin B-12, red cell folate, plasma sodium, potassium, chloride, and urea, blood sugar, serum albumin, globulin, bilirubin, aspartate amino transferase, $\gamma$ glutamyltransferase, calcium, phosphate, IgA, IgG, and thyroid function tests. Stool microscopy and culture showed no pathogens. Chest $x$ ray and plain abdominal $x$ ray were normal. His faecal fat excretion was raised at $35 \mathrm{mmol} /$ day.

He proceeded to upper gastrointestinal endoscopy (Olympus GIF 1T) to examine the upper gastrointestinal tract and to obtain a small bowel biopsy specimen. The only visible abnormality was in the third part of the duodenum where a sessile polyp of $5 \mathrm{~mm}$ in diameter, with a number of much smaller polyps lying adjacent, was found (Fig 1). The largest polyp and the duodenum away from the lesion were biopsied with large forceps (Olympus FB 13K). Dissecting microscopy and histology of the duodenal mucosa showed the typical appearances of untreated coeliac disease with subtotal villous atrophy. Biopsy specimens of the polyp showed a malignant tumour (see below).

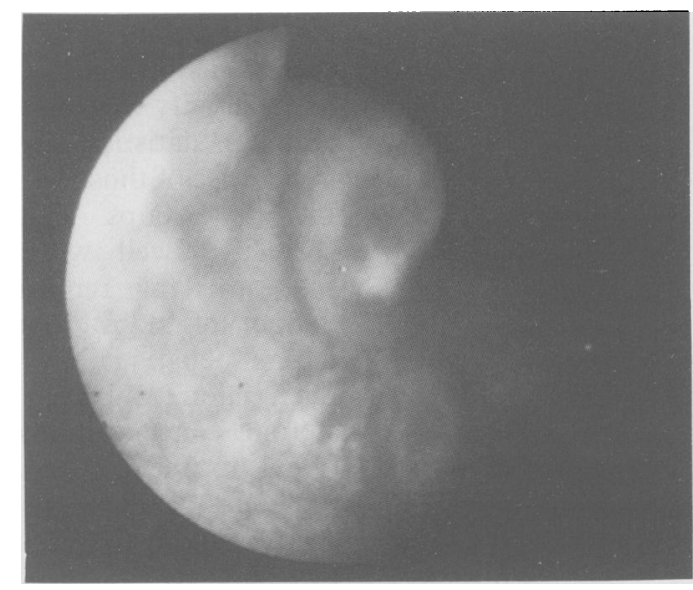

Figure 1: Endoscopic appearance of sessile polyps in third part of duodenum. 


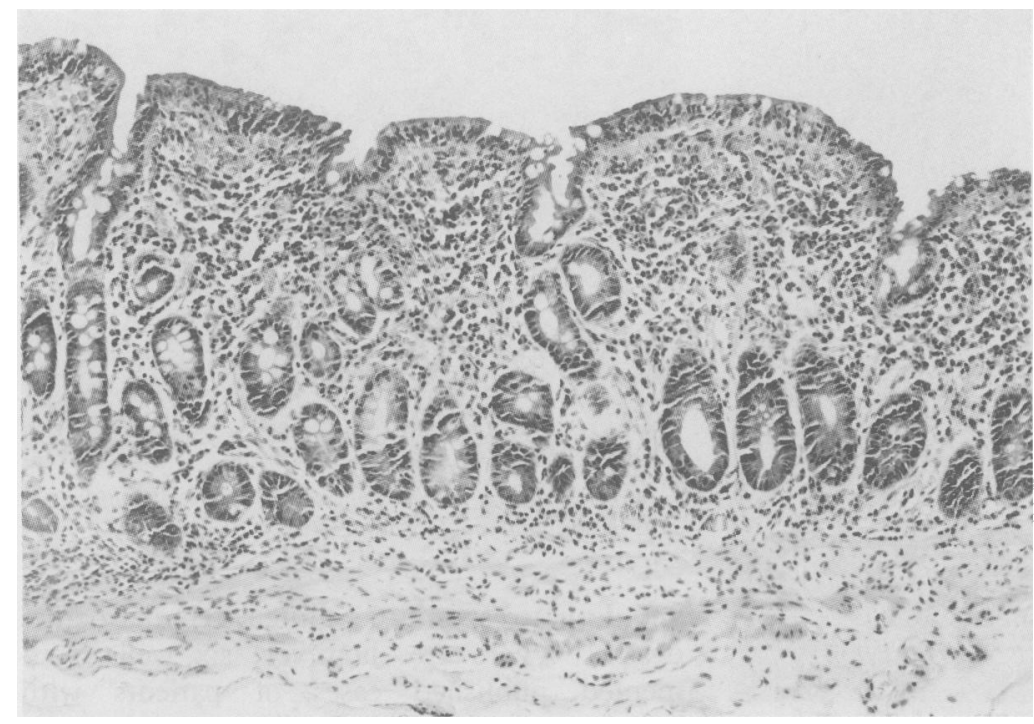

Figure 2: Fejunum: subtotal villous atrophy and intraepithelial lymphocytes typical of coeliac disease. Haematoxylin $\mathcal{E}$ eosin, original magnification $\times 100$.

Figure 3: Fejunum: biopsy specimen taken after treatment showing partial recovery of villi. $H \mathcal{E} E$, original magnification $\times 156$.

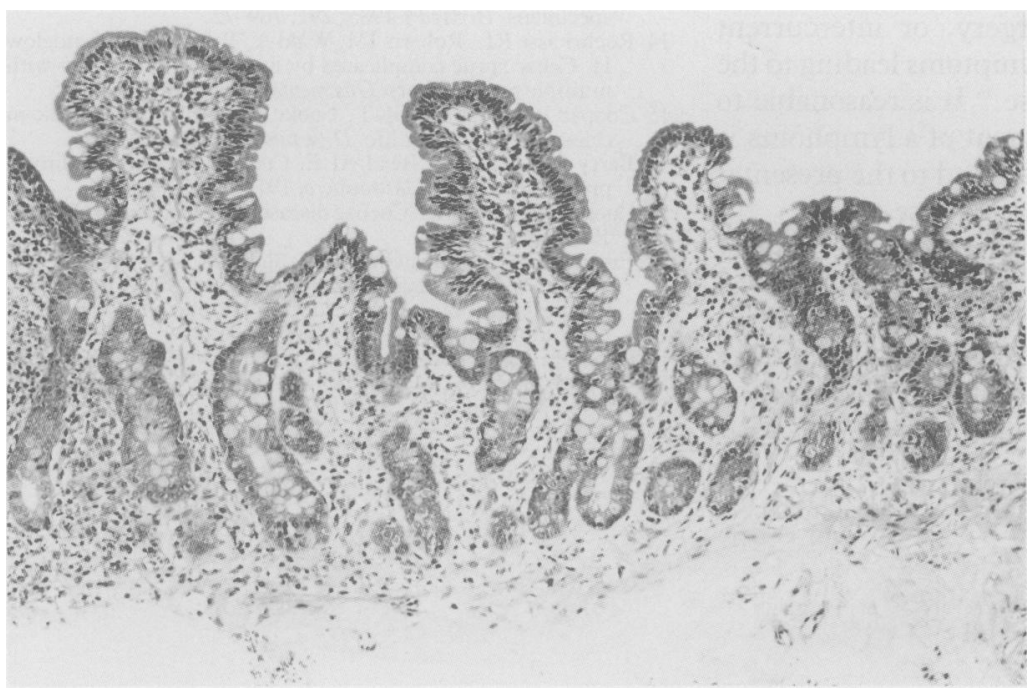
and representative mesenteric lymph nodes biopsied. The full thickness jejunal biopsy specimen confirmed subtotal atrophy (Fig 2). In the third part of the duodenum a localised area of many tiny polyps of $1-2 \mathrm{~mm}$ in diameter were found but no other foci of malignancy were identified (see below). A lymph node adjacent to the involved duodenum was enlarged but not infiltrated with tumour. The other biopsy specimens were normal.

A diagnosis was made of coeliac disease presenting with a complicating malignancy. $\mathrm{He}$ recovered uneventfully from surgery and was started on a gluten free diet. It was decided to treat him with chemotherapy because if this was a coeliac lymphoma these are often multifocal at presentation. ${ }^{8} \mathrm{He}$ received six courses of cyclophosphamide, vincristine, and prednisolone, which he tolerated well. After five months on a gluten free diet his abdominal symptoms had settled, upper gastrointestinal endoscopy was normal and jejunal biopsy showed considerable morphological recovery of the mucosa with partial villous atrophy (Fig 3). He remained well for 28 months after diagnosis of the malignancy when he suffered a fractured skull and died in another hospital. At necropsy the spleen was found to be small and there were a number of large pinkish lymph nodes in the mesentery of the small bowel. No histology was performed.

\section{Histology of the malignant tumour of the duodenum}

Biopsy specimens of the duodenal nodule (Fig 4) taken at endoscopy showed superficial ulceration and infiltration by large pleomorphic cells (Fig 5) with mitotic figures. The tumour cells were negative for leucocyte common antigen UCHLl, cytokeratin (CAM 5.2), and factor VIII related antigen. Despite negative immune markers it was concluded that this was a malignant process of uncertain histiogenesis. Early lymphoma was thought to be the most likely diagnosis, although anaplastic carcinoma could not be excluded. In the resected duodenum, no other foci of pleomorphic cells were found. The adjacent enlarged lymph node showed a prominent T-zone reaction with sinus histiocytosis. No malignant cells were seen

\section{Discussion}

In this paper we have reported the fortuitous early diagnosis of a malignant tumour of the duodenum in a patient with coeliac disease, allowing successful treatment of the tumour.

The most controversial aspect of this case is the nature of the pleomorphic cell infiltrate in the duodenal biopsy, especially as cell markers were negative. The differential diagnosis was between pseudomalignancy, premalignant lymphoid proliferation, and malignancy. The presence of mitoses and extreme pleomorphism of the cells in a patient with a disease which predisposes to malignant change would make the diagnosis of pseudomalignancy unsafe. Focal collections of histiocyte-like cells have been described in coeliac small bowel mucosa adjacent to areas of ulceration and in coeliac patients who have later developed lymphoma. ${ }^{8-10}$ Coeliac patients with non-specific ulceration of the small bowel may later develop lymphoma. "Such a premalignant state was a possible diagnosis in our case but we think it less likely because of the pronounced pleomorphism and mitoses and the absence of small bowel ulceration at endoscopy, small bowel meal, laparotomy, or in the resected specimen. It is our view that the duodenal lesion seen in our patient was malignant and that it is likely to be a primitive lymphoma. An alternative, but less likely diagnosis would be an undifferentiated carcinoma. Coeliac lymphoma is often multifocal and discrete microscopic foci of tumour are likely to be present. ${ }^{38}$ These foci cannot be seen radiologically or at laparotomy. 


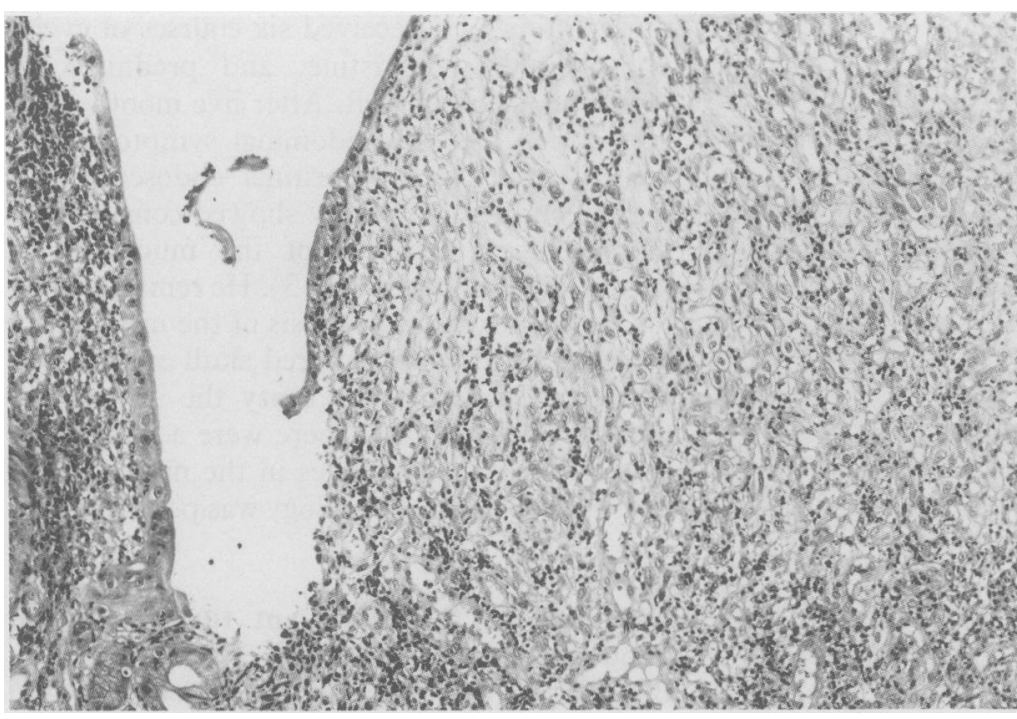

Figure 4: Duodenal nodule (on right) with attenuated epithelial surface. $H \mathcal{E} E$, original magnification $\times 150$.

Therefore if a cure is to be attempted chemotherapy as well as surgery is usually necessary.
An interesting aspect of this case was the early diagnosis of duodenal malignancy by upper gastrointestinal endoscopy. It seems likely that if this patient had had a conventional jejunal biopsy instead of an endoscopic small bowel biopsy the duodenal malignant lesion would have only come to light at a much later stage when the prognosis would be much worse. Distal duodenal biopsies with large endoscopic forceps allow satisfactory diagnosis of small bowel disease, ${ }^{12} 13$ and increasingly this technique is being used. Our case, and other reported cases of gastric lymphoma in coeliac disease diagnosed endoscopically, show the advantage of visualising the upper gastrointestinal tract. ${ }^{14}$ This experience suggests that endoscopy of the upper gastrointestinal tract should be part of the assessment of patients with coeliac disease, particularly when underlying malignancy is suspected.

Our case also illustrates the importance of considering malignancy in the older patient who presents for the first time with coeliac disease. In one series, one in 10 patients presenting with coeliac disease at age 50 or over developed lymphoma within four years of the diagnosis of coeliac disease. ${ }^{15}$ It is sometimes unclear why coeliac disease presents at a particular time, but in other cases an event - for example, an enteric infection, pregnancy, surgery, or intercurrent illness - may precipitate symptoms leading to the diagnosis of coeliac disease. ${ }^{16}$ It is reasonable to suppose that the development of a lymphoma is yet another event which can lead to the presentation and diagnosis of coeliac disease.

There has been considerable controversy about whether patients with small bowel lymphoma and subtotal villous atrophy in small bowel remote from areas of tumorous involvement have coeliac disease or not. ${ }^{7}$ Most such patients have advanced lymphoma at diagnosis

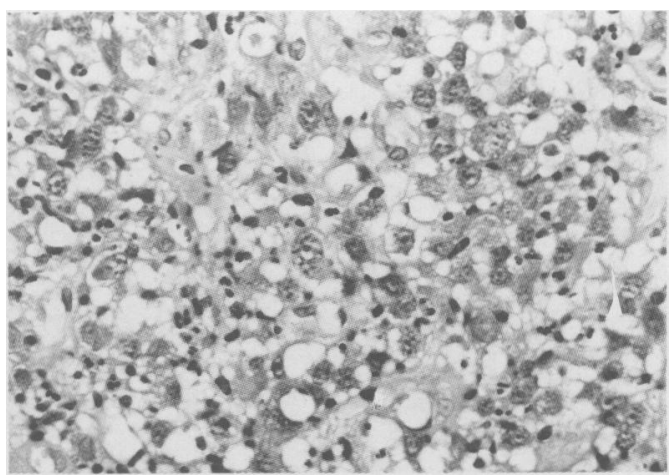

Figure 5: Detail of pleomorphic cells in duodenal nodule. $H \mathcal{F} E$, original magnification $\times 624$.

and do not respond to a gluten free diet before death. ${ }^{37}$ There are, however, six well documented published cases of patients with lymphoma and subtotal villous atrophy who have responded to a gluten free diet after successful treatment of the lymphoma. ${ }^{18} 19$

It has been our view that patients with lymphoma and subtotal villous atrophy remote from the tumour should be regarded as having coeliac disease. ${ }^{17}$ The present case provides further evidence for this.

1 Holmes GKT, Stokes PL, Sorahan TM, Prior P, Waterhouse JAH, Cooke WT. Coeliac disease, gluten free diet and malignancy. Gut 1976; 17: 612-9.

2 Selby WS, Gallagher ND. Malignancy in a 19 year experience of adult celiac disease. Dig Dis Sci 1979; 24: 684-7.

3 Swinson CM, Slavin G, Coles EC, Booth CC. Coeliac diseas and malignancy. Lancet 1983; i: 111-5.

4 Isaacson PG, O'Connor NTJ, Spencer J, et al. Malignant histiocytosis of the intestine: a T-cell lymphoma. Lancet 1985; ii: 688-91.

5 Loughran TP, Kolin ME, Deeg HJ. T-cell intestinal lymphoma associated with celiac sprue. Ann Intern Med 1986; 104: 44-7.

6 Salter DM, Krajewski AS, Dewar AE. Immunophenotype analysis of malignant histiocytosis of the intestine. $\mathcal{J}$ Clin Pathol 1986; 39: 8-15.

7 Cooper BT, Holmes GKT, Ferguson R, Cooke WT. Celiac disease and malignancy. Medicine (Baltimore) 1980; 59: 249-61

8 Isaacson P, Wright DH. Malignant histiocytosis of the intestine. Its relationship to malabsorption and ulcerative jejunitis. Hum Pathol 1978; 9: 661-77.

9 Isaacson P. Malignant histiocytosis of the intestine: the early histological lesion. Gut 1980; $21: 381-6$.

10 Isaacson PG, Spencer J. Malignant lymphoma of mucosaassociated lymphoid tissue. Histopathology $1987 ; 11: 445-62$

11 Baer AN, Bayless TM, Yardley JH. Intestinal ulceration and malabsorption syndromes. Gastroenterology 1980; 79: 754-65.

12 Scott BB, Jenkins D. Endoscopic small intestinal biopsy. Gastrointest Endosc 1981; 27: 162-7.

13 Mee AS, Burke M, Vallon AG, Newman J, Cotton PB. Small bowel biopsy for malabsorption: comparison of the diagnostic adequacy of endoscopic forceps and capsule biopsy specimens. BrMed $\mathcal{F} 1985 ; 291$ : 769-72.

14 Roehrkasse RL, Roberts IM, Wald A, Talamo TS, Mendelow H. Celiac sprue complicated by lymphoma presenting with multiple gastric ulcers. Gastroenterology 1986; 91: 740-5.

15 Cooper BT, Holmes GKT, Cooke WT. Lymphoma risk in celiac disease of later life. Digestion 1982; 23: 89-92.

16 Barry RE, Baker P, Read ALE. Coeliac disease: the clinical presentation. Clin Gastroenterol 1974; 3: 55-69.

17 Cooper BT, Read AE. Coeliac disease and lymphoma. Q7 Med 1987; 63: 269-74.

18 Freeman HJ Weinstein WM, Shnitka TK, Piercey JR, Wensel RH. Primary abdominal lymphoma. Presenting manifestation of celiac sprue or complicating dermatitis manifestation of celiac sprue or complicatin

19 Camilleri M, Krausz T, Lewis PD, Hodgson HJF, Pallis CA Chadwick VS. Malignant histiocytosis and encephalomyeloradiculopathy complicating coeliac disease. Gut 1983 24: 441-7 